Argonne

The Precision of Product Consistency Tests with Environmental Assessment Glass

Chemical and Fuel Cycle Technologies Division 


\section{About Argonne National Laboratory}

Argonne is a U.S. Department of Energy laboratory managed by UChicago Argonne, LLC under contract DE-AC02-06CH11357. The Laboratory's main facility is outside Chicago, at 9700 South Cass Avenue, Argonne, Illinois 60439. For information about Argonne

and its pioneering science and technology programs, see www.anl.gov.

\section{DOCUMENT AVAILABILITY}

Online Access: U.S. Department of Energy (DOE) reports produced after 1991 and a growing number of pre-1991 documents are available free at OSTI.GOV (http://www.osti.gov/), a service of the US Dept. of Energy's Office of Scientific and Technical Information.

Reports not in digital format may be purchased by the public from the National Technical Information Service (NTIS):

U.S. Department of Commerce

National Technical Information Service

5301 Shawnee Rd

Alexandria, VA 22312

www.ntis.gov

Phone: (800) 553-NTIS (6847) or (703) 605-6000

Fax: (703) 605-6900

Email:orders@ntis.gov

Reports not in digital format are available to DOE and DOE contractors from the Office of Scientific and Technical Information (OSTI):

U.S. Department of Energy

Office of Scientific and Technical Information

P.O. Box 62

Oak Ridge, TN 37831-0062

www.osti.gov

Phone: (865) 576-8401

Fax: (865) 576-5728

Email: reports@osti.gov

\section{Disclaimer}

This report was prepared as an account of work sponsored by an agency of the United States Government. Neither the United States Government nor any agency thereof, nor UChicago Argonne, LLC, nor any of their employees or officers, makes any warranty, express or implied, or assumes any legal liability or responsibility for the accuracy, completeness, or usefulness of any information, apparatus, product, or process disclosed, or represents that its use would not infringe privately owned rights. Reference herein to any specific commercial product, process, or service by trade name, trademark, manufacturer, or otherwise, does not necessarily constitute or imply its endorsement, recommendation, or favoring by the United States Government or any agency thereof. The views and opinions of document authors expressed herein do not necessarily state or reflect those of the United States Government or any agency thereof, Argonne National Laboratory, or UChicago Argonne, LLC. 
ANL/CFCT-20/35

The Precision of Product Consistency Tests with Environmental Assessment Glass

prepared by

W.L. Ebert

Chemical and Fuel Cycle Technologies Division, Argonne National Laboratory

C.M. Jantzen

College of Sciences \& Engineering, University of South Carolina Aiken

October 2020 


\section{CONTENTS}

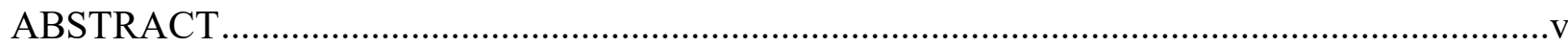

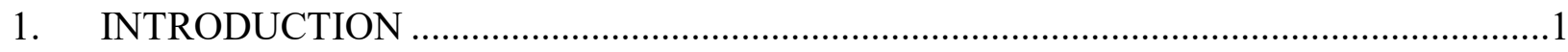

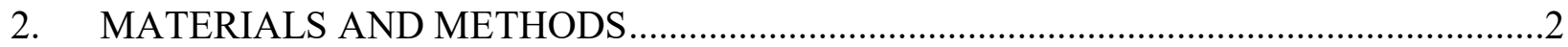

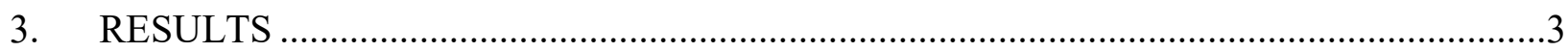

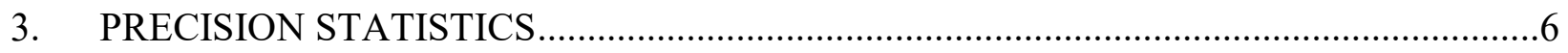

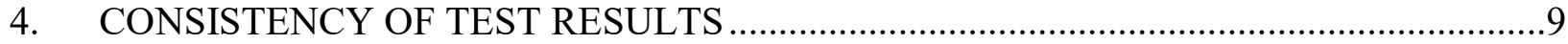

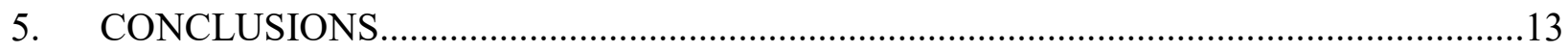

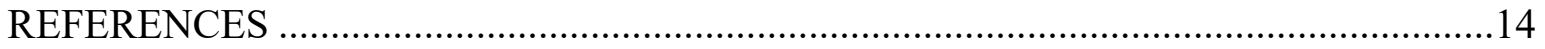




\section{FIGURES}

1. Mean values of NL(B), NL(Li), NL(Na), and NL(Si) for PCT-A tests with EA glass

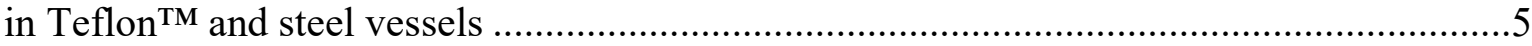

2. Values of (a) $h$-consistency statistic and (b) $k$ - consistency statistic for PCT-A tests

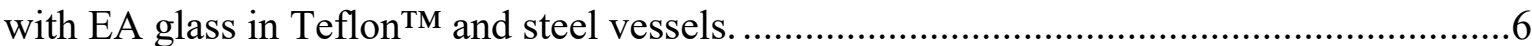

3. Measured ranges of expected values for tests with EA glass conducted in Teflon ${ }^{\mathrm{TM}}$ vessels (dashed lines) and steel vessels (solid lines) based on average $\pm I(\mathrm{R})$ 7 


\section{TABLES}

1. Composition of Environmental Assessment glass, oxide mass percent .............................2

2. Results of PCT with EA Glass in Teflon ${ }^{\mathrm{TM}}$ Vessels ......................................................4

3. Results of PCT with EA Glass in Steel Vessels .............................................................5

4. Summary of Results as Normalized Mass Loss .......................................................13

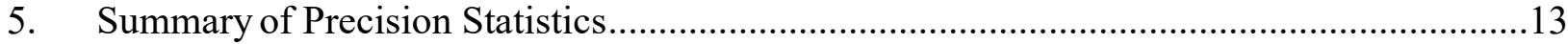

6. Summary of $h$-Consistency and $k$-Consistency Values ............................................15

7. $\quad I(\mathrm{R})$ Values for Tests in Teflon ${ }^{\mathrm{TM}}$ and Steel Vessels .....................................................15 


\title{
THE PRECISION OF PRODUCT CONSISTENCY TESTS WITH ENVIRONMENTAL ASSESSMENT GLASS
}

\begin{abstract}
Several series of triplicate tests conducting following the ASTM C1285 product consistency test method have been performed using samples of Environmental Assessment glass in Teflon ${ }^{\mathrm{TM}}$ and steel test vessels. The results of tests with test parameters within the ranges specified in the PCT method A procedure were used to calculate repeatability and reproducibility precision statistics for tests in each type of vessel. These show the test response and test precision attained in tests conducted in Teflon ${ }^{\mathrm{TM}}$ and stainless steel test vessels are statistically indistinguishable.
\end{abstract}




\section{INTRODUCTION}

The ASTM-International standard method C1285 Product Consistency Test (PCT) is used routinely to measure the chemical durability of waste glasses and other waste forms [1]. The method quantifies the durability using the solution concentrations generated after a crushed material is immersed in a leachant under specific conditions The PCT method A (PCT-A) specifies narrow ranges of test parameter values that are acceptable, including leachant composition, glass size fraction, glass-to-leachant mass ratio, temperature, and test duration. It also specifies that tests be conducted in a stainless steel vessel, in triplicate, and with triplicate blank tests conducted in parallel. Many tests were conducted in Teflon ${ }^{\mathrm{TM}}$ vessels as the method was developed. The PCT-A response is also being used as an acceptance requirement for high- and low-activity waste glasses to be generated at the Hanford Waste Treatment (or Vitrification) Plant. The precision of PCT-A tests must be known with confidence to ensure acceptable waste forms are sufficiently durable for safe disposal and acceptable waste glasses are not rejected.

The so-called Environmental Assessment (EA) glass was developed to provide a benchmark for the durability of high-level radioactive waste (HLW) glasses produced with tank wastes at the Savannah River Site [2]. The glass composition was specified in the Environmental Assessment performed for the Defense Waste Processing Facility and the response of PCT-A with the EA glass is used as a threshold for acceptable HLW glasses in the Waste Acceptance Preliminary Specifications (WAPS) [3].

A large number of PCT have been conducted with the EA glass during development of the test method. This report summarizes the results of a study in which several sets of test data were used to calculate the precision statistics for tests conducted in Teflon ${ }^{\mathrm{TM}}$ and steel vessels. The study was conducted to supplement recent analyses of the precision statistics for PCT conducted with ARM-1 and SRM 623 reference glasses [4]. 


\section{MATERIALS AND METHODS}

A 1000-pound batch of EA glass produced by Corning Glass Works in about 1990 remains under stewardship of the Savannah River National Laboratory and samples taken from this source have been provided to other laboratories. The target composition and compositions measured at Corning and the Savannah River Site (SRS) are given in Table 1 [2].

Table 1. Composition of Environmental Assessment glass, oxide mass percent

\begin{tabular}{llllllll}
\hline Oxide & Target & Corning & SRS & Oxide & Target & Corning & SRS \\
\hline $\mathrm{Al}_{2} \mathrm{O}_{3}$ & 3.67 & 3.70 & 3.60 & $\mathrm{MgO}$ & 4.66 & 1.72 & 1.79 \\
$\mathrm{~B}_{2} \mathrm{O}_{3}$ & 11.12 & 11.3 & 11.16 & $\mathrm{MnO}$ & 1.34 & 1.34 & 1.36 \\
$\mathrm{CaO}$ & 1.13 & 1.12 & 1.23 & $\mathrm{Na} 2$ & 16.71 & 16.8 & 16.88 \\
$\mathrm{Fe}_{2} \mathrm{O}_{3}$ & 8.08 & 7.38 & 7.58 & $\mathrm{NiO}$ & 0.61 & 0.57 & 0.53 \\
$\mathrm{FeO}$ & 0.89 & 1.48 & 1.59 & $\mathrm{SiO}_{2}$ & 48.95 & 48.73 & 48.76 \\
$\mathrm{~K}_{2} \mathrm{O}$ & 0.04 & 0.047 & 0.04 & $\mathrm{TiO}_{2}$ & 0.71 & 0.70 & 0.65 \\
$\mathrm{La}_{2} \mathrm{O}_{3}$ & 0.41 & 0.42 & 0.28 & $\mathrm{ZnO}_{2}$ & - & - & 0.26 \\
$\mathrm{Li}_{2} \mathrm{O}$ & 4.28 & 4.26 & 4.21 & $\mathrm{ZrO}_{2}$ & 0.41 & 0.46 & 0.48 \\
\hline
\end{tabular}

Most tests were conducted in either commercial Type 304L stainless steel vessels or commercial perfluoroalkoxy (PFA) Teflon ${ }^{\mathrm{TM}}$ vessels. One test series was conducted in a Type 304L vessel made for transporting samples between field storage sites and laboratory facilities, which had a considerably rougher surface than the other steel vessels [5]. 


\section{RESULTS}

The test conditions and results reported for triplicate PCT-A conducted with EA glass in Teflon ${ }^{\mathrm{TM}}$ and steel vessels are summarized in Tables 2 and 3. The "Test Set" identifier was assigned to distinguish sets of triplicate tests conducted by a particular researcher that are considered to be independent entries for the analysis of test precision and the "Test ID" is the test identifier used by the researcher. The "Mass Glass" and "Mass Water" values were reported by the researcher and the " $w / g$ Ratio" is the water/glass mass ratio calculated from those values. Only the results of tests with $w / g$ ratios in the range $10.0 \pm 0.1$ specified in the PCT-A method were used to calculate the precision statistics. The "pH, [B], [Li], [Na], and [Si]" values were reported by the researcher and the normalized mass loss values "NL(B), NL(Li), NL(Na), and NL(Si)" values were calculated from the reported solution concentrations to assess the precision statistics by using Equation 1

$$
N L(i)=\frac{C(i) w}{g S_{s p} f(i)}
$$

with the reported masses of water $(w)$ and glass $(g)$, a specific surface area of $S_{s p}=0.020 \mathrm{~m}^{2} / \mathrm{g}$, and elemental mass fractions of $f(\mathrm{~B})=0.0347, f(\mathrm{Li})=0.0196, f(\mathrm{Na})=0.125$, and $f(\mathrm{Si})=0.228$. The $\mathrm{pH}$ values measured at room temperature are included for completeness but not used to evaluate the test precision. The $\mathrm{pH}$ values provide a qualitative indication that all tests proceeded properly, but are not used to quantify the extent of material dissolution. The average $\mathrm{pH}$ value for tests in Teflon ${ }^{\mathrm{TM}}$ vessels was 11.74 and the average $\mathrm{pH}$ value for test in steel vessels was 11.90. Teflon $^{\mathrm{TM}}$ vessels are known to be permeable to air and the slightly lower $\mathrm{pH}$ in tests conducted in Teflon ${ }^{\mathrm{TM}}$ vessels could be due an effect of dissolved $\mathrm{CO}_{2}$. Borosilicate glass dissolution rates are typically lower in solutions with lower $\mathrm{pH}$ values.

Test series $\mathrm{C} 1$ and $\mathrm{C} 2$ included four replicate tests, but only the results of the first three tests in series $\mathrm{C} 1$ and $\mathrm{C} 2$ were included in the analyses so that triplicate tests from each participant were used for the precision statistics. The results of the fourth tests were arbitrarily omitted from the statistics analyses, but are included in Table 3 for completeness. Test Set B6 was conducted in non-commercial steel vessels and those results were excluded from the precision statistics, but are compared with the precision determined using the other tests.

The calculated values of $\mathrm{NL}(\mathrm{B}), \mathrm{NL}(\mathrm{Li}), \mathrm{NL}(\mathrm{Na})$, and $\mathrm{NL}(\mathrm{Si})$ were used to calculate the precision statistics rather than the measured solution concentrations to take the $\mathrm{w} / \mathrm{g}$ ratio of each test into account. This is because differences in the $\mathrm{w} / \mathrm{g}$ ratio even within the range specified for PCT-A test affects the test response. The $\mathrm{NL}(\mathrm{Si})$ values do not provide a reliable measure of the extent of material dissolution in PCT-A tests because the release of Si to solution is affected by solution saturation and the formation of surface alteration layers. However, the silicon concentration is usually the highest of the constituents in EA glass and the most analytically accurate measure of the solution composition. It provides a valuable measure of the test precision. 
Table 2. Results of PCT with EA Glass in Teflon ${ }^{\mathrm{TM}}$ Vessels

\begin{tabular}{|c|c|c|c|c|c|c|c|c|c|c|c|c|c|}
\hline $\begin{array}{l}\text { Test } \\
\text { Set }\end{array}$ & Test ID & $\begin{array}{c}\text { Mass } \\
\text { Glass, g }\end{array}$ & $\begin{array}{c}\text { Mass } \\
\text { Water, g }\end{array}$ & $\begin{array}{c}w / g \\
\text { Ratio }\end{array}$ & $\mathrm{pH}$ & $\begin{array}{l}{[\mathrm{B}],} \\
\mathrm{mg} / \mathrm{L}\end{array}$ & $\begin{array}{l}{[\mathrm{Li}],} \\
\mathrm{mg} / \mathrm{L}\end{array}$ & $\begin{array}{l}{[\mathrm{Na}],} \\
\mathrm{mg} / \mathrm{L}\end{array}$ & $\begin{array}{l}{[\mathrm{Si}],} \\
\mathrm{mg} / \mathrm{L}\end{array}$ & $\begin{array}{c}\mathrm{NL}(\mathrm{B}), \\
\mathrm{g} / \mathrm{m}^{2}\end{array}$ & $\begin{array}{c}\mathrm{NL}(\mathrm{Li}) \\
\mathrm{g} / \mathrm{m}^{2}\end{array}$ & $\begin{array}{c}\mathrm{NL}(\mathrm{Na}), \\
\mathrm{g} / \mathrm{m}^{2}\end{array}$ & $\begin{array}{c}\mathrm{NL}(\mathrm{Si}), \\
\mathrm{g} / \mathrm{m}^{2}\end{array}$ \\
\hline \multirow{3}{*}{ A1 } & EA-7-1 & 35.00 & 3.49 & 10.03 & 11.53 & 609.42 & 192.06 & 1685.50 & 908.43 & 8.81 & 4.91 & 6.76 & 2.00 \\
\hline & EA-7-2 & 35.06 & 3.54 & 9.90 & 11.58 & 615.07 & 187.92 & 1724.34 & 909.33 & 8.78 & 4.75 & 6.83 & 1.97 \\
\hline & EA-7-3 & 35.07 & 3.51 & 9.99 & 11.59 & 634.81 & 195.74 & 1770.69 & 938.30 & 9.14 & 4.99 & 7.08 & 2.06 \\
\hline \multirow{3}{*}{$\mathrm{A} 2$} & EA-7-4 & 34.98 & 3.52 & 9.94 & 11.63 & 638.54 & 204.01 & 1771.35 & 956.44 & 9.14 & 5.17 & 7.04 & 2.08 \\
\hline & EA-7-5 & 34.96 & 3.51 & 9.96 & 11.63 & 649.05 & 208.11 & 1789.02 & 965.06 & 9.32 & 5.29 & 7.13 & 2.11 \\
\hline & EA-7-6 & 35.00 & 3.53 & 9.92 & 11.55 & 584.70 & 186.73 & 1644.01 & 892.60 & 8.35 & 4.72 & 6.52 & 1.94 \\
\hline \multirow{3}{*}{ B1 } & EA-T1 & 35.72 & 3.57 & 10.01 & 11.84 & 521 & 168 & 1580 & 854 & 7.51 & 4.29 & 6.32 & 1.87 \\
\hline & EA-T2 & 25.80 & 2.58 & 10.00 & 11.83 & 607 & 174 & 1620 & 886 & 8.75 & 4.44 & 6.48 & 1.94 \\
\hline & EA-T3 & 30.70 & 3.07 & 10.00 & 11.84 & 578 & 172 & 1600 & 869 & 8.33 & 4.39 & 6.40 & 1.91 \\
\hline \multirow{3}{*}{ E1 } & EA-1-7-1 & 39.51 & 4.00 & 9.88 & 11.80 & 567.96 & 210.71 & 1738.35 & 1048.41 & 8.08 & 5.31 & 6.87 & 2.27 \\
\hline & EA-1-7-2 & 39.56 & 4.00 & 9.89 & 11.79 & 593.57 & 211.19 & 1819.70 & 1061.93 & 8.46 & 5.33 & 7.20 & 2.30 \\
\hline & EA-1-7-3 & 39.66 & 4.00 & 9.92 & 11.80 & 605.97 & 212.86 & 1857.20 & 1070.91 & 8.66 & 5.38 & 7.37 & 2.33 \\
\hline \multirow{3}{*}{ E2 } & EA-2-7-1 & 39.65 & 4.00 & 9.91 & 11.86 & 468.52 & 163.27 & 1380.80 & 780.29 & 6.69 & 4.13 & 5.47 & 1.70 \\
\hline & EA-2-7-2 & 39.53 & 4.00 & 9.88 & 11.88 & 610.00 & 225.05 & 1854.87 & 1128.56 & 8.69 & 5.67 & 7.33 & 2.45 \\
\hline & EA-2-7-3 & 39.45 & 4.00 & 9.86 & 11.88 & 523.05 & 171.77 & 1542.60 & 832.21 & 7.43 & 4.32 & 6.09 & 1.80 \\
\hline
\end{tabular}


Table 3. Results of PCT with EA Glass in Steel Vessels

\begin{tabular}{|c|c|c|c|c|c|c|c|c|c|c|c|c|c|}
\hline $\begin{array}{l}\text { Test } \\
\text { Set }\end{array}$ & Test ID & $\begin{array}{c}\text { Mass } \\
\text { Glass, g }\end{array}$ & $\begin{array}{c}\text { Mass } \\
\text { Water, g }\end{array}$ & $\begin{array}{c}w / g \\
\text { Ratio }\end{array}$ & $\mathrm{pH}$ & $\begin{array}{l}{[\mathrm{B}],} \\
\mathrm{mg} / \mathrm{L}\end{array}$ & $\begin{array}{l}{[\mathrm{Li}],} \\
\mathrm{mg} / \mathrm{L}\end{array}$ & $\begin{array}{l}{[\mathrm{Na}]} \\
\mathrm{mg} / \mathrm{L}\end{array}$ & $\begin{array}{l}{[\mathrm{Si}]} \\
\mathrm{mg} / \mathrm{L}\end{array}$ & $\begin{array}{c}\mathrm{NL}(\mathrm{B}), \\
\mathrm{g} / \mathrm{m}^{2}\end{array}$ & $\begin{array}{c}\mathrm{NL}(\mathrm{Li}) \\
\mathrm{g} / \mathrm{m}^{2}\end{array}$ & $\begin{array}{c}\mathrm{NL}(\mathrm{Na}) \\
\mathrm{g} / \mathrm{m}^{2}\end{array}$ & $\begin{array}{c}\mathrm{NL}(\mathrm{Si}), \\
\mathrm{g} / \mathrm{m}^{2}\end{array}$ \\
\hline \multirow{4}{*}{$\mathrm{C} 1$} & SS-EA-19-1 & 18.953 & 1.897 & 9.99 & 11.92 & 577.41 & 180.78 & 1633.95 & 798.81 & 8.31 & 4.61 & 6.53 & 1.75 \\
\hline & SS-EA-19-2 & 19.046 & 1.907 & 9.99 & 11.90 & 566.13 & 177.48 & 1604.19 & 791.43 & 8.15 & 4.52 & 6.41 & 1.73 \\
\hline & SS-EA-19-3 & 19.096 & 1.916 & 9.97 & 11.95 & 576.06 & 180.48 & 1635.24 & 794.04 & 8.27 & 4.59 & 6.52 & 1.74 \\
\hline & SS-EA-19-4* & 18.892 & 1.894 & 9.97 & 11.91 & 584.31 & 183.60 & 1650.21 & 803.25 & 8.40 & 4.67 & 6.58 & 1.76 \\
\hline \multirow{4}{*}{$\mathrm{C} 2$} & EA-SS-15-1 & 15.064 & 1.493 & 10.09 & 11.98 & 596.10 & 190.26 & 1670.40 & 846.96 & 8.67 & 4.90 & 6.74 & 1.87 \\
\hline & EA-SS-15-2 & 15.041 & 1.497 & 10.05 & 11.92 & 601.41 & 191.52 & 1692.06 & 852.09 & 8.71 & 4.91 & 6.80 & 1.88 \\
\hline & EA-SS-15-3 & 15.026 & 1.508 & 9.96 & 11.93 & 587.04 & 196.68 & 1640.88 & 848.55 & 8.43 & 5.00 & 6.54 & 1.85 \\
\hline & EA-SS-15-4* & 15.006 & 1.497 & 10.02 & 11.95 & 572.67 & 193.11 & 1606.35 & 830.64 & 8.27 & 4.94 & 6.44 & 1.83 \\
\hline \multirow{3}{*}{ D1 } & SS-EA-1-7-1 & 16.082 & 1.608 & 10.00 & 11.78 & 656.50 & 204.53 & 1808.68 & 956.18 & 9.46 & 5.22 & 7.24 & 2.10 \\
\hline & SS-EA-1-7-2 & 16.086 & 1.601 & 10.05 & 11.77 & 654.11 & 206.95 & 1794.88 & 963.87 & 9.47 & 5.30 & 7.21 & 2.12 \\
\hline & SS-EA-1-7-3 & 16.058 & 1.604 & 10.01 & 11.78 & 637.71 & 199.26 & 1754.74 & 936.13 & 9.20 & 5.09 & 7.03 & 2.06 \\
\hline \multirow{3}{*}{ D2 } & SS-EA-2-7-1 & 16.030 & 1.607 & 9.98 & 11.76 & 626.15 & 192.80 & 1711.27 & 909.10 & 9.00 & 4.91 & 6.83 & 1.99 \\
\hline & SS-EA-2-7-2 & 16.032 & 1.608 & 9.97 & 11.77 & 614.53 & 191.51 & 1695.62 & 905.34 & 8.83 & 4.87 & 6.76 & 1.98 \\
\hline & SS-EA-2-7-3 & 16.017 & 1.604 & 9.99 & 11.72 & 629.50 & 195.76 & 1723.18 & 925.18 & 9.06 & 4.99 & 6.88 & 2.03 \\
\hline \multirow{3}{*}{ B2 } & EA-1 & 29.81 & 2.98 & 10.00 & 12.06 & 490 & 150 & 1580 & 684 & 7.06 & 3.83 & 6.32 & 1.50 \\
\hline & EA-2 & 30.31 & 3.03 & 10.00 & 11.93 & 560 & 149 & 1560 & 688 & 8.07 & 3.80 & 6.24 & 1.51 \\
\hline & EA-3 & 30.13 & 3.01 & 10.01 & 12.05 & 520 & 142 & 1520 & 651 & 7.50 & 3.63 & 6.09 & 1.43 \\
\hline \multirow{3}{*}{ B3 } & EA-4 & 29.71 & 2.97 & 10.00 & 11.94 & 574 & 153 & 1550 & 699 & 8.27 & 3.90 & 6.20 & 1.53 \\
\hline & EA-5 & 30.01 & 3.00 & 10.00 & 11.93 & 562 & 154 & 1520 & 695 & 8.10 & 3.93 & 6.08 & 1.52 \\
\hline & EA-6 & 29.41 & 2.94 & 10.00 & 12.00 & 560 & 149 & 1610 & 698 & 8.07 & 3.80 & 6.44 & 1.53 \\
\hline \multirow{3}{*}{ B4 } & EA-7 & 31.89 & 3.18 & 10.03 & 11.91 & 571 & 159 & 1510 & 721 & 8.25 & 4.07 & 6.06 & 1.59 \\
\hline & EA-8 & 30.85 & 3.08 & 10.02 & 11.91 & 536 & 132 & 1480 & 613 & 7.74 & 3.37 & 5.93 & 1.35 \\
\hline & EA-9 & 34.21 & 3.42 & 10.00 & 11.96 & 585 & 137 & 1600 & 648 & 8.43 & 3.50 & 6.40 & 1.42 \\
\hline \multirow{3}{*}{ B5 } & EA-10 & 29.90 & 2.98 & 10.03 & 11.89 & 578 & 146 & 1580 & 687 & 8.36 & 3.74 & 6.34 & 1.51 \\
\hline & EA-11 & 40.40 & 4.04 & 10.00 & 11.95 & 490 & 112 & 1360 & 496 & 7.06 & 2.86 & 5.44 & 1.09 \\
\hline & EA-12 & 29.54 & 2.95 & 10.01 & 11.89 & 555 & 141 & 1560 & 632 & 8.01 & 3.60 & 6.25 & 1.39 \\
\hline \multirow{3}{*}{ B6 } & CUA-EA-1* & 33.51 & 3.3520 & 10.00 & 11.77 & 442 & 143 & 1200 & 727 & 6.37 & 3.65 & 4.80 & 1.59 \\
\hline & CUA-EA-2* & 40.03 & 4.0003 & 10.01 & 11.68 & 315 & 130 & 977 & 635 & 4.54 & 3.32 & 3.91 & 1.39 \\
\hline & CUA-EA-4* & 81.97 & 8.1962 & 10.00 & 11.82 & 472 & 195 & 1650 & 980 & 6.80 & 4.97 & 6.60 & 2.15 \\
\hline
\end{tabular}

*Results excluded from precision statistics. 


\section{PRECISION STATISTICS}

Statistical analyses of the test responses quantified by the normalized mass loss values are summarized by using the values defined in the following equations provided in ASTM Standard E691-19 [6]. The average of the responses $x_{p}$ measured by each participant (Test Set) $p$ in $n$ replicate tests is

$\bar{x}_{p}=\sum x_{p} / n$

and the standard deviation for the results of replicate tests by participant $p$ is

$s_{p}=\left[\left(\sum\left(x_{p}-\bar{x}_{p}\right)^{2}\right) /(n-1)\right]^{1 / 2}$.

This is a measure of the within-laboratory (intralaboratory) precision. In this study, $n=3$ and $p=5$ for tests in Teflon ${ }^{\mathrm{TM}}$ vessels and $p=8$ for tests in steel vessels. Values of $\bar{x}_{p}$ and $s_{p}$ are included as the average and standard deviation values that were given for each Test Set in Tables 2 and 3. The consensus average for the $p$ participants is

$\bar{x}=\sum \bar{x}_{P} / p$.

The standard deviation of the averages for replicate tests by the same participant from the consensus average is

$S_{x}=\left[\left(\sum\left(\bar{x}_{p}-\bar{x}\right)^{2}\right) /(p-1)\right]^{1 / 2}$.

The pooled within-laboratory (intralaboratory) standard deviation is

$S_{r}=\left[\sum s_{p}^{2} / p\right]^{1 / 2}$.

The standard deviation for the normal distribution of laboratory means is

$s_{L}=\left(s_{\bar{x}}^{2}+\left(s_{r}^{2} / n\right)\right)^{1 / 2}$.

This gives the estimated standard deviation for repeatability of measurements made within a single laboratory. The between-laboratory (interlaboratory) estimate of precision is

$s_{R}=\left(s_{\bar{x}}^{2}+s_{r}^{2}(n-1) / n\right)^{1 / 2}$.

This is the reproducibility standard deviation. Smaller values of the standard deviation represent higher test precision. 
Two other expressions are used to quantify the repeatability and reproducibility of the tests:

- $\quad$ The estimated $95 \%$ repeatability level is $I(\mathrm{r})=2.83 \bullet \mathrm{sr}$. On the basis of test error alone, the absolute value of the difference of two test results obtained in the same laboratory will exceed $I(\mathrm{r})$ only approximately $5 \%$ of the time.

- $\quad$ The estimated $95 \%$ reproducibility level is $I(\mathrm{R})=2.83{ }^{{ }^{\circ} \mathrm{SR}}$. On the basis of test error alone (including within- and between-laboratory components), the absolute value of the difference between two test results obtained in different laboratories will exceed $I(\mathrm{R})$ only approximately $5 \%$ of the time.

The mean values and standard deviations for the normalized mass loss values calculated for the different sets of triplicate tests conducted using Teflon ${ }^{\mathrm{TM}}$ and steel vessels are summarized in Table 4 and plotted in Figure 1.

Table 4. Summary of Results as Normalized Mass Loss

\begin{tabular}{|c|c|c|c|c|c|c|c|c|}
\hline & \multicolumn{2}{|c|}{ NL(B) } & \multicolumn{2}{|c|}{ NL(Li) } & \multicolumn{2}{|c|}{$\mathrm{NL}(\mathrm{Na})$} & \multicolumn{2}{|c|}{$\mathrm{NL}(\mathrm{Si})$} \\
\hline \multicolumn{9}{|c|}{ Tests in Teflon ${ }^{\mathrm{TM}}$ Vessels } \\
\hline A1 & 8.91 & \pm 0.20 & 4.88 & \pm 0.12 & 6.89 & \pm 0.17 & 2.01 & \pm 0.04 \\
\hline $\mathrm{A} 2$ & 8.94 & \pm 0.51 & 5.06 & \pm 0.30 & 6.90 & \pm 0.33 & 2.04 & \pm 0.09 \\
\hline B1 & 8.20 & \pm 0.63 & 4.37 & \pm 0.08 & 6.40 & \pm 0.08 & 1.91 & \pm 0.04 \\
\hline E1 & 8.40 & \pm 0.29 & 5.34 & \pm 0.04 & 7.14 & \pm 0.25 & 2.30 & \pm 0.03 \\
\hline $\mathrm{E} 2$ & 7.60 & \pm 1.01 & 4.71 & \pm 0.84 & 6.30 & \pm 0.95 & 1.98 & \pm 0.41 \\
\hline Pooled Avg & 8.41 & & 4.87 & & 6.73 & & 2.05 & \\
\hline \multicolumn{9}{|c|}{ Tests in Steel Vessels } \\
\hline $\mathrm{C} 1$ & 8.24 & \pm 0.09 & 4.57 & \pm 0.04 & 6.49 & \pm 0.07 & 1.74 & \pm 0.01 \\
\hline $\mathrm{C} 2$ & 8.60 & \pm 0.15 & 4.94 & \pm 0.06 & 6.69 & \pm 0.14 & 1.87 & \pm 0.01 \\
\hline D1 & 9.38 & \pm 0.15 & 5.20 & \pm 0.11 & 7.16 & \pm 0.12 & 2.09 & \pm 0.04 \\
\hline D2 & 8.96 & \pm 0.12 & 4.92 & \pm 0.06 & 6.82 & \pm 0.06 & 2.00 & \pm 0.02 \\
\hline $\mathrm{B} 2$ & 7.54 & \pm 0.51 & 3.75 & \pm 0.11 & 6.22 & \pm 0.12 & 1.48 & \pm 0.04 \\
\hline B3 & 8.15 & \pm 0.11 & 3.88 & \pm 0.07 & 6.24 & \pm 0.18 & 1.53 & \pm 0.01 \\
\hline B4 & 8.14 & \pm 0.36 & 3.64 & \pm 0.37 & 6.13 & \pm 0.24 & 1.45 & \pm 0.12 \\
\hline B5 & 7.81 & \pm 0.67 & 3.40 & \pm 0.47 & 6.01 & \pm 0.50 & 1.33 & \pm 0.22 \\
\hline B6* & 5.90 & \pm 1.20 & 3.98 & \pm 0.88 & 5.10 & \pm 1.37 & 1.71 & \pm 0.39 \\
\hline Pooled Avg & 8.35 & & 4.12 & & 6.47 & & 1.62 & \\
\hline
\end{tabular}

*Results excluded from pooled average.

The pooled average results for all four elements are slightly lower in tests conducted in steel vessels than in tests conducted in Teflon ${ }^{\mathrm{TM}}$ vessels. As mentioned above, tests conducted in Teflon $^{\mathrm{TM}}$ vessels had a slightly lower average $\mathrm{pH}$ value than tests in steel vessels (11.74 compared to 11.90) that could be due ingress of $\mathrm{CO}_{2}$. However, borosilicate glass dissolution rates are lower at lower solution $\mathrm{pH}$ values and the responses seen in Figure 1 indicate a slightly higher dissolution rate occurred in tests conducted in Teflon ${ }^{\mathrm{TM}}$ vessels. 


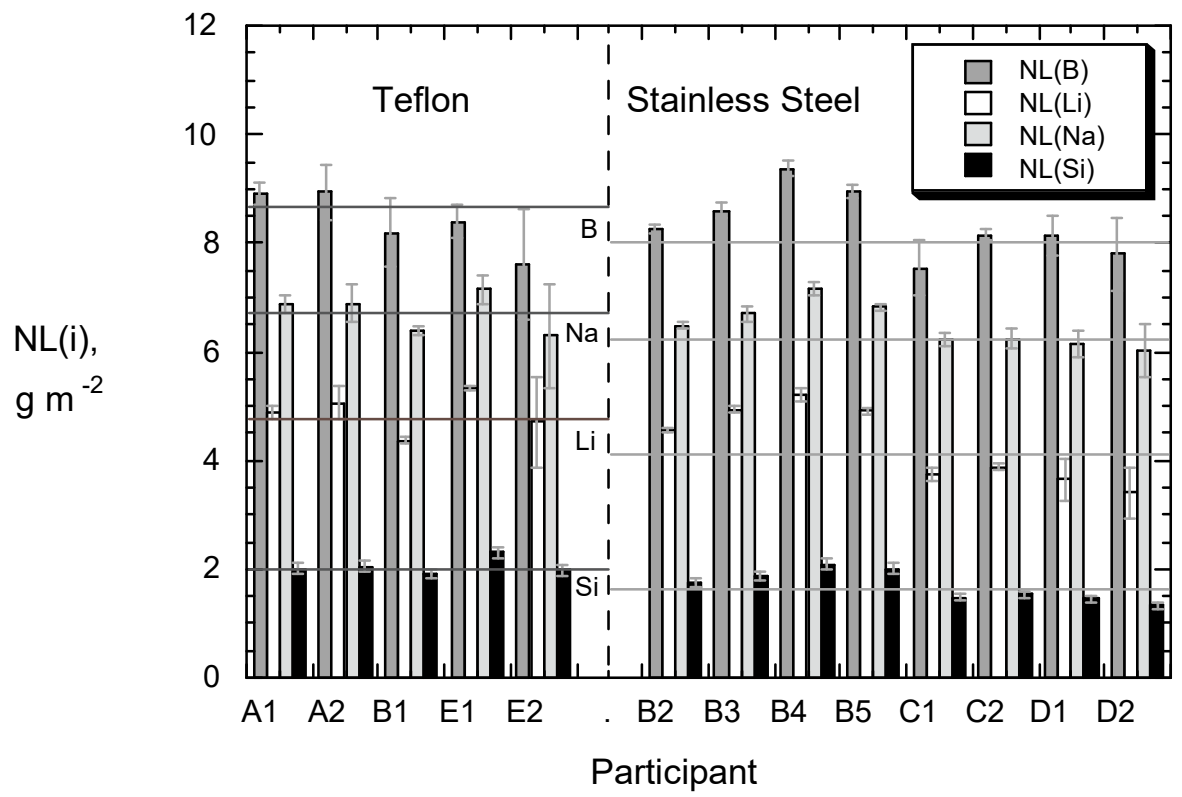

Figure 1. Mean values of NL(B), NL(Li), NL(Na), and NL(Si) for PCT-A tests with EA glass in Teflon ${ }^{\mathrm{TM}}$ and steel vessels. Lines show pooled mean values and uncertainty bars show mean \pm 1 standard deviation.

The precision statistics for the tests conducted in Teflon ${ }^{\mathrm{TM}}$ and stainless steel are summarized in Table 5.

Table 5. Summary of Precision Statistics

\begin{tabular}{|c|c|c|c|c|c|c|c|}
\hline & $\bar{x}_{p}$ & $s_{\bar{x}}$ & $s_{r}$ & $s_{L}$ & $s_{R}$ & $I(\mathrm{r})$ & $I(\mathrm{R})$ \\
\hline \multicolumn{8}{|c|}{ Tests in Teflon ${ }^{\mathrm{TM}}$ Vessels } \\
\hline $\mathrm{B}$ & 8.41 & 0.553 & 0.600 & 0.431 & 0.738 & 1.68 & 2.07 \\
\hline $\mathrm{Li}$ & 4.87 & 0.365 & 0.405 & 0.280 & 0.492 & 1.13 & 1.38 \\
\hline $\mathrm{Na}$ & 6.73 & 0.360 & 0.469 & 0.238 & 0.526 & 1.31 & 1.47 \\
\hline $\mathrm{Si}$ & 2.05 & 0.150 & 0.188 & 0.103 & 0.215 & 0.527 & 0.601 \\
\hline \multicolumn{8}{|c|}{ Tests in Steel Vessels } \\
\hline $\mathrm{B}$ & 8.35 & 0.699 & 0.338 & 0.689 & 0.752 & 0.947 & 2.13 \\
\hline $\mathrm{Li}$ & 4.29 & 0.720 & 0.223 & 0.716 & 0.743 & 0.625 & 2.10 \\
\hline $\mathrm{Na}$ & 6.47 & 0.483 & 0.222 & 0.476 & 0.515 & 0.621 & 1.46 \\
\hline $\mathrm{Si}$ & 1.69 & 0.289 & 0.091 & 0.287 & 0.298 & 0.255 & 0.844 \\
\hline
\end{tabular}

${ }^{\text {a }}$ Symbols defined in text. 


\section{CONSISTENCY OF TEST RESULTS}

A one-way analysis of variance was used to evaluate the internal precision of triplicate tests conducted by each researcher and the precision between data sets. These analyses indicate whether the data provide a sufficiently consistent measure of the test response and provide values of statistical precision. They also identify inconsistent data that should be investigated by the participants. In this application, the repeatability represents the variability between test results obtained by a single operator with a specific test apparatus using test specimens taken at random from the material prepared for use in the study. Reproducibility represents the variability between test results obtained by different researchers or in different test series by the same researcher. All test specimens were taken at random from the common source material (in this case, glass made by Corning Glass Works), but differences in the particle size distribution and effective removal of fines likely occurred in batches prepared for use in different studies. The statistical parameters in Table 5 were used to determine the repeatability (consistency within a set of triplicate tests) and the reproducibility (consistency between sets of triplicate tests) that can be expected for PCTs. Variations due to sample preparation effects, including particle shape and size distributions, will add to the imprecision between researchers but is not expected to affect the test consistency within a set of triplicate tests. Those effects are expected to be negligible in this study.

The between-laboratory consistency is conveniently determined by the $h$-consistency statistic, which is defined as the difference between the value measured by a participant $\left(\bar{x}_{p}\right)$ and the consensus value $(\bar{x})$ divided by the standard deviation of the averages $\left(s_{\bar{x}}\right)$ :

$$
h=\frac{\left(\bar{x}_{p}-\bar{x}\right)}{s_{\bar{x}}}
$$

The $h$-consistency statistic can be used to evaluate the overall variability of the analyses among the participants (in this case, among the data sets) and to compare the results from one participant to the results from all the other participants. At the $0.5 \%$ significance level, the critical values of $h$ for five and eight participants are \pm 1.49 and \pm 2.15 , respectively (see Table 5 in Ref. 6). The critical value aids in the decision of whether or not the deviation in the results of a particular laboratory exceeds that expected due to random error and warrants investigation. We used the critical value to identify results that differ significantly from the consensus values and exceed the test precision of the majority of test results.

The within-laboratory consistency is determined by the $k$-consistency statistic, which is defined as the standard deviation for a participant $\left(s_{p}\right)$ divided by the repeatability standard deviation $\left(s_{r}\right)$ :

$$
k=\frac{s_{p}}{s_{r}}
$$


The $k$-consistency statistic provides a measure of how the variability within a laboratory compares with the combined variability of all laboratories. The critical $k$-values for five and eight participants conducting triplicate tests are 1.82 and 2.06, respectively (see Table 5 in Ref. 6). Note that a very small $k$-consistency parameter value indicates a less sensitive measurement scale compared with the other laboratories, which may also warrant investigation. In this case, the k-value indicates the relative precision of each Test set.

The $h$-consistency and $k$-consistency values for tests in Teflon ${ }^{\mathrm{TM}}$ and steel vessels are summarized in Table 6 and plotted in Figures $2 \mathbf{2 a}$ and $\mathbf{2 b}$, respectively. Figure 2a shows that the $h$-values for all measurements except NL(Si) in set E1 and NL(B) in Set E2 conducted using Teflon $^{\mathrm{TM}}$ vessels are within the critical values. Figure $\mathbf{2 b}$ shows that the $k$-values are exceeded by the $\mathrm{Li}, \mathrm{Na}$, and $\mathrm{Si}$ concentrations measured in Set E2 conducted in Teflon ${ }^{\mathrm{TM}}$ vessels and in Set B5 conducted in steel vessels. This means that the variation in the results for replicate tests in Sets E2 and B5 are higher than the variations in other sets. The imprecision may be related to the test execution or the solution analysis. Because three of the four analyzed elements exceed the critical value, the imprecision is attributed to test execution.

Table 6. Summary of $h$-Consistency and $k$-Consistency Values

\begin{tabular}{lcccccccc}
\hline \multicolumn{3}{c}{$h$-consistency statistic } & \multicolumn{5}{c}{$k$-consistency statistic } \\
\cline { 2 - 9 } & NL(B) & NL(Li) & NL(Na) & NL(Si) & NL(B) & NL(Li) & NL(Na) & NL(Si) \\
\hline \multicolumn{7}{c}{ Tests in Teflon ${ }^{\text {TM }}$ Vessels } \\
\hline A1 & 0.903 & 0.029 & 0.455 & -0.260 & 0.335 & 0.305 & 0.353 & 0.222 \\
A2 & 0.956 & 0.515 & 0.473 & -0.028 & 0.855 & 0.736 & 0.700 & 0.481 \\
B1 & -0.386 & -1.374 & -0.901 & -0.942 & 1.047 & 0.189 & 0.167 & 0.184 \\
E1 & -0.016 & 1.282 & 1.161 & 1.685 & 0.486 & 0.096 & 0.539 & 0.153 \\
E2 & -1.457 & -0.452 & -1.188 & -0.454 & 1.681 & 2.078 & 2.017 & 2.159 \\
\hline & & & 7 & & & & & \\
C1 & 0.322 & 0.633 & 0.569 & 0.419 & 0.255 & 0.202 & 0.303 & 0.100 \\
C2 & 0.832 & 1.136 & 1.000 & 0.865 & 0.445 & 0.251 & 0.616 & 0.138 \\
D1 & 1.942 & 1.509 & 1.963 & 1.639 & 0.454 & 0.486 & 0.517 & 0.379 \\
D2 & 1.349 & 1.116 & 1.270 & 1.313 & 0.352 & 0.266 & 0.272 & 0.270 \\
B2 & -0.678 & -0.506 & 0.011 & -0.481 & 1.495 & 0.492 & 0.541 & 0.483 \\
B3 & 0.186 & -0.330 & 0.064 & -0.307 & 0.323 & 0.302 & 0.827 & 0.050 \\
B4 & 0.172 & -0.654 & -0.170 & -0.579 & 1.067 & 1.660 & 1.102 & 1.342 \\
B5 & -0.301 & -0.997 & -0.417 & -1.002 & 1.982 & 2.122 & 2.235 & 2.391 \\
B6 & -3.026 & -0.190 & -2.296 & 0.324 & 3.544 & 3.927 & 6.181 & 4.296 \\
\hline
\end{tabular}




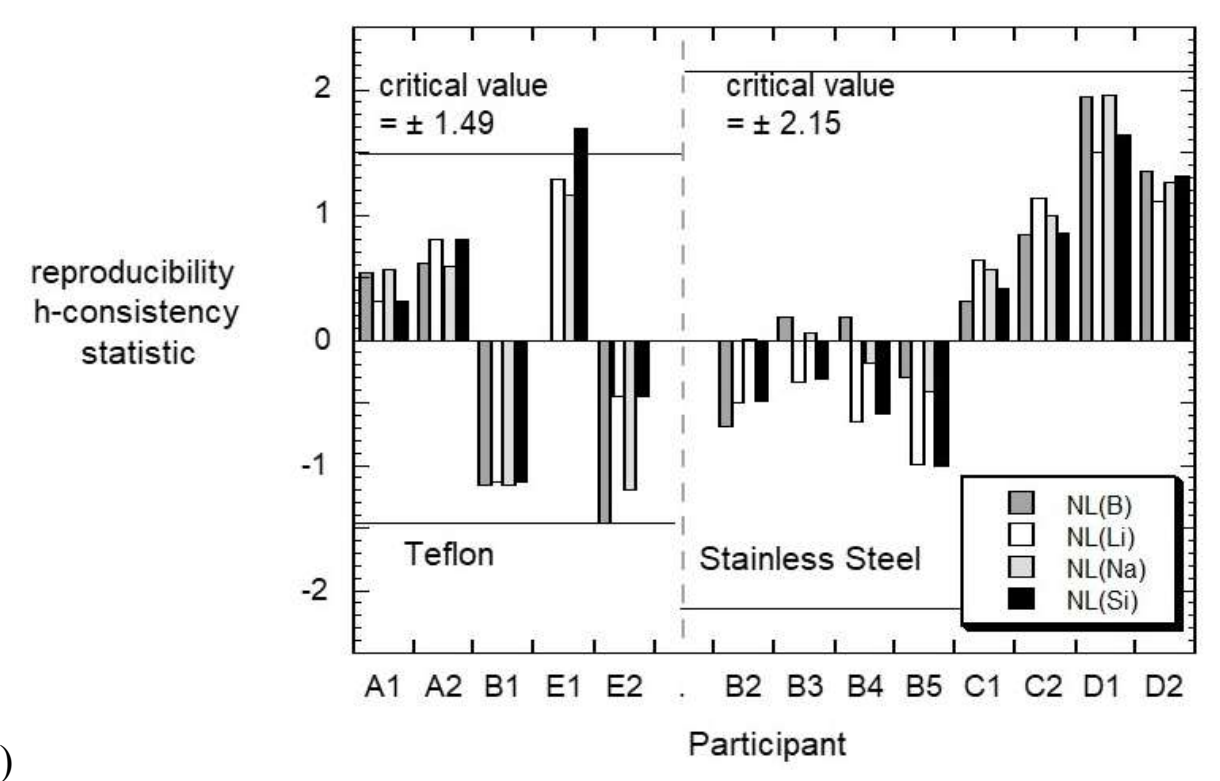

(a)

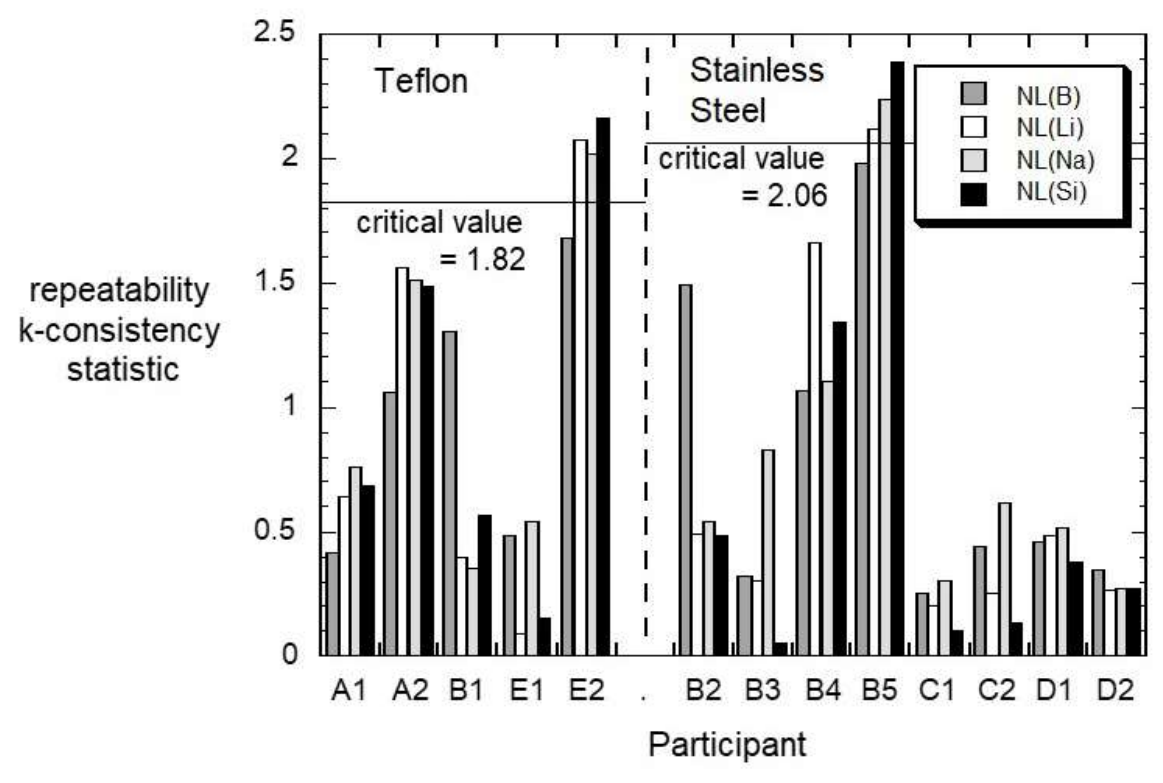

(b)

Figure 2. Values of (a) $h$-consistency statistic and (b) $k$ - consistency statistic for PCT-A tests with EA glass in Teflon ${ }^{\mathrm{TM}}$ and steel vessels.

The expected values for PCTs conducted with a particular reference glass are given by consensus values $I(\mathrm{r})$ for repeatability and $I(\mathrm{R})$ for reproducibility. Two values measured by the same researcher that differing by more than the value of $I(\mathrm{r})$ should be considered suspect. Likewise, two values measured at different laboratories differing by more than the value of $I(\mathrm{R})$ should be considered suspect. The expected repeatability and reproducibility of tests are included in Table 7, which gives the expected values for tests conducted with EA glasses with the parameter values specified for PCT-A. These are given in terms of the normalized mass loss values rather than the measured concentrations to take variations in the $w / g$ mass ratio allowed within PCT-A $(10.0 \pm 0.5)$ into account. 
Table 7. $I(\mathrm{R})$ Values for Tests in Teflon ${ }^{\mathrm{TM}}$ and Steel Vessels

\begin{tabular}{cccccc}
\hline & \multicolumn{2}{c}{ Teflon $^{\text {TM }}$} & & \multicolumn{2}{c}{ Steel } \\
\cline { 2 - 3 } \cline { 5 - 6 } \cline { 5 - 6 } NL(B) & minimum & maximum & & minimum & maximum \\
\hline NL(Li) & 6.341 & 10.477 & & 6.226 & 10.481 \\
NL(Na) & 5.253 & 6.252 & & 2.185 & 6.392 \\
NL(Si) & 1.448 & 2.649 & & 0.842 & 7.929 \\
\hline
\end{tabular}

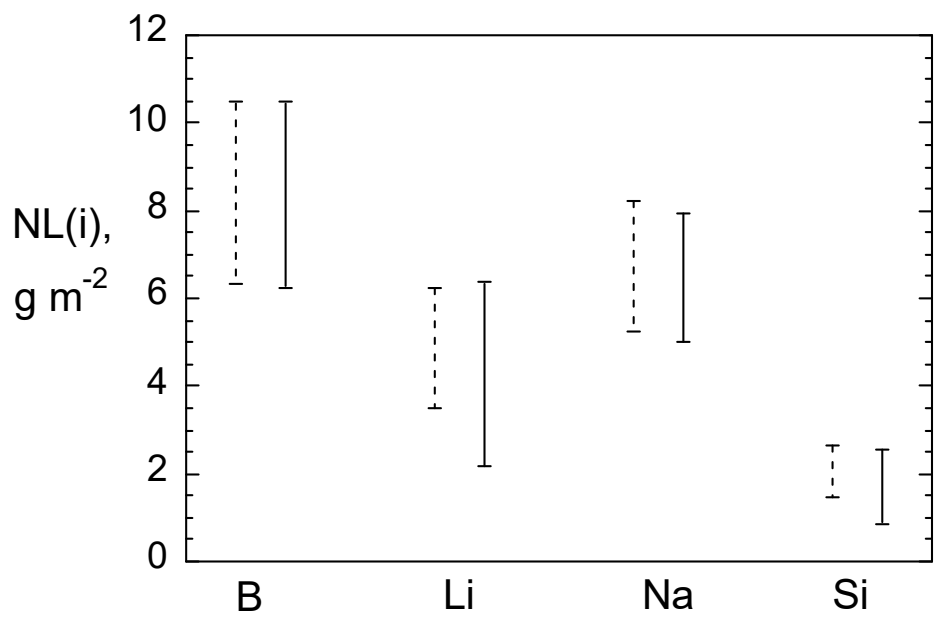

Figure 3. Measured ranges of expected values for tests with EA glass conducted in Teflon ${ }^{\mathrm{TM}}$ vessels (dashed lines) and steel vessels (solid lines) based on average $\pm I(\mathrm{R})$.

A sixth set of triplicate tests was conducted by researcher B (referred to as Set B6) in vessels constructed of unpolished steel pipe with end caps. The average results of triplicate tests in Test Set B6 fall in the centers of the ranges for tests in Teflon ${ }^{\mathrm{TM}}$ and steel vessels. Those results had $k$-consistency statistic values of 3.54, 3.93, 6.18, and 4.30 for NL(B), NL(Li), NL(Na), and $\mathrm{NL}(\mathrm{Si})$, respectively, all of which greatly exceed the critical value of 2.06 . The $h$-consistency statistic values were $-3.03,-0.19,-2.30$, and 0.32 for $\mathrm{NL}(\mathrm{B}), \mathrm{NL}(\mathrm{Li}), \mathrm{NL}(\mathrm{Na})$, and $\mathrm{NL}(\mathrm{Si})$, respectively. The values for NL(B) and $\mathrm{NL}(\mathrm{Na})$ exceed the critical value of -2.15 . Because half of the tests in stainless steel contributing to the precision statistics were conducted by researcher $\mathrm{B}$, the deviations are attributed to unspecified effects of the vessel rather than test execution. 


\section{CONCLUSIONS}

The results of several series of replicate PCT conducted with EA glass by different researchers at Savannah River and Pacific Northwest National Laboratories were used to calculate and compare the precision statistics for tests conducted in Teflon ${ }^{\mathrm{TM}}$ and steel vessels. Results were treated as individual sets of triplicate tests to calculate within-set and between-set precision statistics for five sets of tests in Teflon ${ }^{\mathrm{TM}}$ vessels and eight sets of tests in commercial steel vessels. Test results were used to calculate normalized mass loss values based on the concentrations of $\mathrm{B}, \mathrm{Li}, \mathrm{Na}$, and $\mathrm{Si}$, and only tests conducted with water/glass mass ratios within the range $10.0 \pm 0.1 \mathrm{~g} / \mathrm{g}$ were used in the analyses. Both the mean responses and precision values were similar for tests in Teflon $^{\mathrm{TM}}$ and steel vessels. A few results for tests in both types of vessel exceeded the critical values for $h$ - and $k$-consistency statistics that gauge the individual results, which means the data sets represent the appropriate level of sensitivity to test execution and analysis. 


\section{References}

1. ASTM (2020a). Standard Test Methods for Determining Chemical Durability of Nuclear Waste Glasses: The Product Consistency Test (PCT). Standard C1285-14, Annual Book of ASTM Standards Vol. 12.01, ASTM-International, West Conshohocken, PA (2020).

2. Jantzen, C.M., Bibler, N.E., and Beam, D.C. (1993). Characterization of the Defense Waste Processing Facility (DWPF) Environmental Assessment (EA) Glass Standard Reference Material. Westinghouse Savannah River Co. report WSRC-TR-92-346, Rev. 1.

3. Applewhite-Ramsey, A., \& Sproull, J.F. (1993). Waste acceptance product specifications for vitrified high-level waste forms. Westinghouse Savannah River Co. report WSRC-MS-93002, Rev1.

4. Olson, K.M., Smith, G.L., and Marschman, S.C. (1995). Product Consistency Testing of Three Reference Glasses in Stainless Steel and Perfluoroalkoxy Resin Vessels. Pacific Northwest National Laboratory report PNL-10497.

5. Ebert, W.L. (2019). The Precision of Product Consistency Tests with Reference Glasses ARM-1 and SRM 623. Argonne National Laboratory report ANL/CFCT-19/29.

6. ASTM (2020b). Standard Practice for Conducting an Interlaboratory Study to Determine the Precision of a Test Method. Standard E691-19, Annual Book of ASTM Standards Vol. 14.05, ASTM-International, West Conshohocken, PA. 


\section{Argonne}

Chemical and Fuel Cycle Technologies Division

Argonne National Laboratory

9700 South Cass Avenue, Bldg. 205

Argonne, IL 60439

www.anl.gov

Argonne National Laboratory is a U.S. Department of Energy laboratory managed by UChicago Argonne, LLC 